\title{
Communication
}

\section{Doping-Induced Anisotropic Self-Assembly of Silver Icosahedra in [Pt2Ag23Cl7(PPh3)10] Nanoclusters}

Megalamane S. Bootharaju, Sergey M. Kozlov, Zhen Cao, Moussab Harb, Niladri

Maity, Aleksander Shkurenko, Manas R Parida, Mohamed Nejib Hedhili, Mohamed

Eddaoudi, Omar F. Mohammed, Osman M. Bakr, Luigi Cavallo, and Jean Marie Basset

J. Am. Chem. Soc., Just Accepted Manuscript • DOI: 10.1021/jacs.6b11875 • Publication Date (Web): 09 Jan 2017

Downloaded from http://pubs.acs.org on January 9, 2017

\section{Just Accepted}

"Just Accepted" manuscripts have been peer-reviewed and accepted for publication. They are posted online prior to technical editing, formatting for publication and author proofing. The American Chemical Society provides "Just Accepted" as a free service to the research community to expedite the dissemination of scientific material as soon as possible after acceptance. "Just Accepted" manuscripts appear in full in PDF format accompanied by an HTML abstract. "Just Accepted" manuscripts have been fully peer reviewed, but should not be considered the official version of record. They are accessible to all readers and citable by the Digital Object Identifier (DOI®). "Just Accepted" is an optional service offered to authors. Therefore, the "Just Accepted" Web site may not include all articles that will be published in the journal. After a manuscript is technically edited and formatted, it will be removed from the "Just Accepted" Web site and published as an ASAP article. Note that technical editing may introduce minor changes to the manuscript text and/or graphics which could affect content, and all legal disclaimers and ethical guidelines that apply to the journal pertain. ACS cannot be held responsible for errors or consequences arising from the use of information contained in these "Just Accepted" manuscripts. 
Precise control over composition, size, shape and monodispersity of nanoparticles (NPs) is one of the biggest challenges in materials science. Polydispersity, a wide distribution of size and shape of NPs, prevents achieving precisely defined functional properties and hinders direct comparison and evaluation of NPs. ${ }^{1}$ However, advanced synthetic routes, involving protecting ligands, allow controlling size and composition of the NPs from a few tens of metal atoms to hundreds. These methods led to development of a distinct class of materials called atomically precise $\mathrm{NPs}$, nanoclusters (NCs) or nanomolecules. ${ }^{2-13} \mathrm{NCs}$ gained an extensive research interest both in fundamental and applied sciences not only due to their intriguing optical, ${ }^{14,15}$ photophysical $^{16,17}$ and chemical properties ${ }^{5,18}$ (originated from ultrasmall size and discrete energy levels), but also for their potential application in sensing, ${ }^{5}$ catalysis, ${ }^{19,20}$ bioimaging $^{3}$ and energy-conversion ${ }^{5}$.

Most of the current research has focused mainly on $\mathrm{Au} \mathrm{NCs}{ }^{2,21}$ (e.g., $\mathrm{Au}_{18}, \mathrm{Au}_{25}, \mathrm{Au}_{38}, \mathrm{Au}_{102}$ and $\mathrm{Au}_{133}$ ) due to their highstability, while properties of analogous Ag NCs are largely unexplored. Nevertheless, a handful of $\mathrm{Ag}$ NCs such as $\mathrm{Ag}_{21},{ }^{22} \mathrm{Ag}_{25},{ }^{14}$ $\mathrm{Ag}_{29},{ }^{16} \mathrm{Ag}_{44},{ }^{23,24} \mathrm{Ag}_{67},{ }^{25} \mathrm{Ag}_{136}{ }^{26}$ and $\mathrm{Ag}_{374},{ }^{26}$ including their X-ray crystal structures, have been reported. Subsequently, $\mathrm{AgAu}$ and other alloy $\mathrm{NCs}^{27,28}$ have also been synthesized to obtain enhanced optical ${ }^{29-31}$ and catalytic ${ }^{19}$ properties.

\begin{abstract}
Atomically precise self-assembled architectures of noble metals with unique surface structures are necessary for prospective applications. However, synthesis of such structures based
on silver is challenging due to their instability. In this work, by sized and characterized a rod-shaped charge-neutral, we synthedoped $\mathrm{Ag}$ nanocluster $(\mathrm{NC})$ of $\left[\mathrm{Pt}_{2} \mathrm{Ag}_{23} \mathrm{Cl}_{7}\left(\mathrm{PPh}_{3}\right)_{10}\right]$. Its crystal hedra through the vertex-sharing. Five bridging and two terminal chlorides, and ten $\mathrm{PPh}_{3}$ ligands were found to stabilize the cluster.
Electronic structure simulations corroborated structural and optical characterization of the cluster and provided insights into the effect of Pt dopants on optical properties and stability of the clus-
ter. Our study will open new avenues for designing novel selfassembled NCs using different elemental dopants.
\end{abstract}

The majority of metal NCs reported are isotropic and approximately spherical. Although a few anisotropic Au NCs were developed, ${ }^{2}$ those of $\mathrm{Ag}^{25}$ are rare. In addition to anisotropy and metal nuclearity, NCs containing self-assembled metal nanobuilding blocks ${ }^{32}$ are highly desired for applications as they would provide distinct surface structures. The use of labile ligands (e.g., phosphines) and non-bulky ligands (e.g., halides) for these selfassembled nanostructures would make their surface more accessible. Such self-assembly of metal nanobuilding blocks was previously observed in $\mathrm{Au}^{7,32}$ and its heteroatoms-doped $\mathrm{NCs}^{33-39}$ such as $\left[\mathrm{MAu}_{12} \mathrm{Ag}_{12}\left(\mathrm{PPh}_{3}\right)_{10} \mathrm{Cl}_{7}\right]^{+}, \mathrm{M}=\mathrm{Pt}$ or $\mathrm{Ni}, \mathrm{PPh}_{3}=$ triphenylphosphine, and $\left[\mathrm{Pt}_{2} \mathrm{Au}_{10} \mathrm{Ag}_{13}\left(\mathrm{PPh}_{3}\right)_{10} \mathrm{X}_{7}\right], \mathrm{X}=\mathrm{Cl}$ or $\mathrm{Br}$, due to their high-stability provided by more noble $\mathrm{Au}$ atoms. However, synthesis of these NCs involves multiple steps and preprepared complexes as metal precursors. However, analogous pure Ag or Ag-based doped NCs have not been achieved until now due to synthetic challenges and instability issues caused by the oxidation of less noble $\mathrm{Ag}$ atoms.

In this work, we designed a single-step reaction to synthesize a heteroatom-doped Ag NC, comprising self-assembled Ag building blocks, by using $\mathrm{Pt}$ as the dopant and a labile phosphine, $\mathrm{PPh}_{3}$, and simple $\mathrm{Cl}^{-}$as ligands. Pt was chosen as dopant since $\mathrm{Ag}$ and Pt have different atomic radii (1.65 and $1.77 \AA$, respectively), which was envisaged to prevent the formation of NCs with various degrees of doping. Our synthetic protocol involves the $\mathrm{NaBH}_{4}$ reduction of a mixture of readily available $\mathrm{Ag}$ and $\mathrm{Pt}$ precursors, $\mathrm{AgNO}_{3}$ and $\mathrm{Na}_{2} \mathrm{PtCl}_{6} \cdot 6 \mathrm{H}_{2} \mathrm{O}$ in the presence of $\mathrm{PPh}_{3}$ in $\mathrm{CH}_{3} \mathrm{OH}+\mathrm{CH}_{2} \mathrm{Cl}_{2}$ co-solvents (see Supporting Information, SI for details). The final $\mathrm{NC}$ in $\mathrm{CH}_{2} \mathrm{Cl}_{2}$ was crystallized by layering hexane. Single-crystal XRD (SCXRD) and high-resolution electrospray ionization mass spectrometry (ESI MS) unambiguously revealed the composition of the synthesized product to be $\left[\mathrm{Pt}_{2} \mathrm{Ag}_{23} \mathrm{Cl}_{7}\left(\mathrm{PPh}_{3}\right)_{10}\right]$, possessing self-assembled $\mathrm{Ag}$ icosahedrons (vide infra).

As we had in mind, introduction of Pt as dopant was crucial to obtain a self-assembled cluster with a precise molecular formula and structure. In the absence of the Pt source, the synthesized product (Figure $\mathrm{S} 1$ ) was a hydride-rich $\left[\mathrm{Ag}_{18} \mathrm{H}_{16}\left(\mathrm{PPh}_{3}\right)_{10}\right]^{2+}$ cluster rather than $\left[\mathrm{Ag}_{25} \mathrm{Cl}_{7}\left(\mathrm{PPh}_{3}\right)_{10}\right]^{\mathrm{q}}, \mathrm{q}=$ charge. However, this $\mathrm{Ag}_{18}$ $\mathrm{NC}$ was unstable in common solvents, such as $\mathrm{CH}_{2} \mathrm{Cl}_{2}$, preventing to obtain single-crystals for XRD. Therefore, introducing Pt ions not only enhanced the stability of the final product 
$\left[\mathrm{Pt}_{2} \mathrm{Ag}_{23} \mathrm{Cl}_{7}\left(\mathrm{PPh}_{3}\right)_{10}\right]$ in $\mathrm{CH}_{2} \mathrm{Cl}_{2}$, but also facilitated the growth of single-crystals.

SCXRD analysis of the $\left[\mathrm{Pt}_{2} \mathrm{Ag}_{23} \mathrm{Cl}_{7}\left(\mathrm{PPh}_{3}\right)_{10}\right]$ crystals revealed that it crystallizes in $P 2_{1} / m$ space group (Table $\mathrm{S} 1$ ) and the unit cell contains two clusters (Figure S2). This cluster was found to be charge-neutral, as no counterions were found in its crystal structure, consistent with the ESI MS and theoretical results (vide infra). Moreover, the density functional theory (DFT)-optimized geometry of $\left[\mathrm{Pt}_{2} \mathrm{Ag}_{23} \mathrm{Cl}_{7}\left(\mathrm{PPh}_{3}\right)_{10}\right]$ is very similar to the $\mathrm{X}$-ray structure. The root mean square deviation between the two structures is $0.13 \AA$ when counted on all atoms excluding $\mathrm{C}$ and $\mathrm{H}$ $(0.26 \AA$ when only $\mathrm{H}$ is excluded). The total structure of the cluster comprising a $\mathrm{Pt}_{2} \mathrm{Ag}_{23}$ metal rod is shown in Figure 1.

A

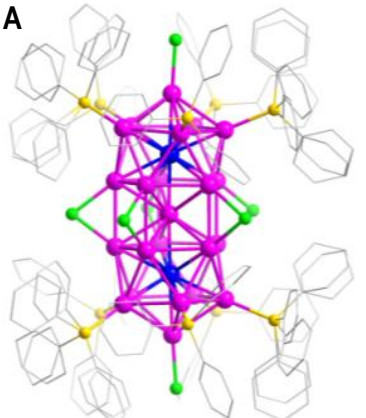

Figure 1. (A) Side-view and (B) top-view of the $\left[\mathrm{Pt}_{2} \mathrm{Ag}_{23} \mathrm{Cl}_{7}\left(\mathrm{PPh}_{3}\right)_{10}\right]$ cluster. Color legends: cyan, $\mathrm{Ag}$; blue, Pt; yellow, $\mathrm{P}$; green, $\mathrm{Cl}$; and gray, $\mathrm{C}$. $\mathrm{H}$ atoms of ligands are omitted for clarity.

Detailed structure analysis of the cluster reveals the presence of two $\mathrm{PtAg}_{12}$ icosahedrons with the $\mathrm{Pt}$ at the center (Figure 2A), self-assembled through the vertex-sharing to form the $\mathrm{Pt}_{2} \mathrm{Ag}_{23}$ metal structure in a rod-shape (Figures $1 \mathrm{~A}$ and $2 \mathrm{~B}$ ). The length of the rod is 1.106(1) $\mathrm{nm}$ (distance between two terminal or apex $\mathrm{Ag}$ atoms). The average $\mathrm{Ag}-\mathrm{Ag}$ and $\mathrm{Ag}-\mathrm{Pt}$ bond distances in the $\mathrm{PtAg}_{12}$ icosahedron are 2.88 (like in bulk Ag), ${ }^{16}$ and $2.74 \AA$, respectively, indicating strong interaction among the $\mathrm{Ag}$ atoms. However, the average distance of $\mathrm{Ag}$ atoms that connect the two icosahedrons is $2.94 \AA$. The $\mathrm{Pt}_{2} \mathrm{Ag}_{23}$ appeared to have an imperfect rod-shape, as it is slightly bent (since the angle between the bonds from the central vertex-shared $\mathrm{Ag}$ atom to the apex $\mathrm{Ag}$ atoms deviates by $3.4^{\circ}$ from $180^{\circ}$ ). This bending would have resulted in clearly different $\mathrm{Ag}-\mathrm{Ag}$ bonds between the two icosahedrons from those within an icosahedron.

Seven $\mathrm{Cl}^{-}$ligands were found to protect the $\mathrm{Pt}_{2} \mathrm{Ag}_{23}$ framework in two different binding modes. Five $\mathrm{Cl}^{-}$ions act as bridging ligands, connecting the two $\mathrm{PtAg}_{12}$ icosahedrons to form a structure shown in Figure 2C. The remaining two $\mathrm{Cl}^{-}$ions are connected to two terminal $\mathrm{Ag}$ atoms of the $\mathrm{Pt}_{2} \mathrm{Ag}_{23}$ rod in the form of dangling $\mathrm{Ag}-\mathrm{Cl}$ bonds. The average $\mathrm{Ag}-\mathrm{Cl}$ bond lengths are $\sim 2.50 \AA$. The $\mathrm{P}$ atoms of ten $\mathrm{PPh}_{3}$ ligands bind with the remaining ten uncoordinated $\mathrm{Ag}$ sites to give the total $\left[\mathrm{Pt}_{2} \mathrm{Ag}_{23} \mathrm{Cl}_{7}\left(\mathrm{PPh}_{3}\right)_{10}\right]$ structure (Figure 2D). The average Ag-P distance was found to be $2.42 \AA$. Top view of the cluster, Figure 1B, shows that the $\mathrm{PPh}_{3}$ ligands in the two icosahedrons are in an eclipsed configuration. Alternatively, the $\mathrm{Pt}_{2} \mathrm{Ag}_{23}$ structure of the cluster can be interpreted based on the connectivity of ligands and metal atoms. A linear metal core of Pt-Ag-Pt is located deep inside the cluster and not connected to ligands. The remaining $22 \mathrm{Ag}$ atoms form a closed rod-like morphology. Encapsulation of $\mathrm{Pt}_{2} \mathrm{Ag}$ bimetallic core within the $\mathrm{Ag}_{22}$ shell or rod produces the total structure of the $\mathrm{Pt}_{2} \mathrm{Ag}_{23}$ framework (Figure S3).

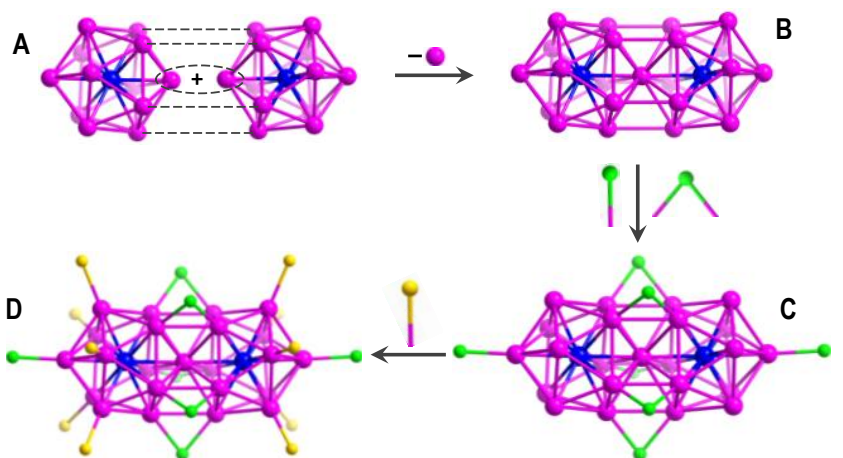

Figure 2. (A) Vertex Ag atoms of two $\mathrm{PtAg}_{12}$ icosahedrons being shared and connected are shown with a dotted ellipse and dotted lines, respectively. (B) Biicosahedral $\mathrm{Pt}_{2} \mathrm{Ag}_{23}$ rod. (C) Bridging and terminal chlorides bind with structure $\mathrm{B}$ to form $\mathrm{Pt}_{2} \mathrm{Ag}_{23} \mathrm{Cl}_{7}$. (D) Capping ten $\mathrm{P}$ atoms of ten $\mathrm{PPh}_{3}$ ligands gives $\mathrm{Pt}_{2} \mathrm{Ag}_{23} \mathrm{Cl}_{5} \mathrm{P}_{10}$. Color legends are the same as in Figure 1.

Subsequently, ESI MS of the cluster was performed to support the formula and the charge obtained from SCXRD. No mass signals for the cluster, both in positive and negative ion modes, confirmed the neutral charge-state. However, a mass peak at $\mathrm{m} / \mathrm{z}$ $\sim 3004$, with 2+ charge, was observed (Figure S4A,B) for a cluster solution that was mixed with $\mathrm{Cs}_{2} \mathrm{CO}_{3}$ solution. The total mass of this peak corresponds to $\left[\mathrm{Pt}_{2} \mathrm{Ag}_{23} \mathrm{Cl}_{7}\left(\mathrm{PPh}_{3}\right)_{10}\right] \mathrm{Cs}_{2}$ and it was further verified by a perfect match of the experimental mass spectrum with the corresponding simulated one (Figure S4C). The existence of the cluster in solution was confirmed from a large shift and broadening of the ${ }^{31} \mathrm{P}$ NMR peak $(2.83 \mathrm{ppm})$ along with a slight shift of the ${ }^{1} \mathrm{H}$ NMR peaks $(\sim 7.32 \mathrm{ppm})$ of the cluster from those of free $\mathrm{PPh}_{3}$ (-5.42 and $\sim 7.23 \mathrm{ppm}$, respectively) (Figures S5,6). Further broadening and shifting of ${ }^{31} \mathrm{P}$ NMR peaks at low-temperature (Figure S7) indicated the partial restricted rotations of $\mathrm{PPh}_{3}$ ligands that were bound to cluster. XPS shows the presence of all the expected elements in the cluster (Figure S8). The $\mathrm{Ag} 3 \mathrm{~d}_{5 / 2}$ peak at $367.8 \mathrm{eV}$ suggests the $\mathrm{Ag}$ valence state to be between $\operatorname{Ag}(0)$ and $\operatorname{Ag}(\mathrm{I})$. Majority of the $\mathrm{Pt}$ was present as $\mathrm{Pt}(0)$ consistent with SCXRD. A minor fraction of unreacted $\mathrm{Pt}(\mathrm{II})$ species, which could not be removed by solvent-washing, was also identified. The yield of the cluster was $\sim 24 \%$ (based on $\mathrm{Ag}$ atoms). The cluster is sensitive to light both in solid- and solutionstates. Nevertheless, it is stable in dark for a day in $\mathrm{CH}_{2} \mathrm{Cl}_{2}$ and more than 25 days in the solid-state (Figure S9).

The optical properties and electronic structure of $\left[\mathrm{Pt}_{2} \mathrm{Ag}_{23} \mathrm{Cl}_{7}\left(\mathrm{PPh}_{3}\right)_{10}\right]$ were further studied both experimentally and theoretically using summation over empty states DFT (SOS-DFT) and time-dependent DFT (TD-DFT). The experimental absorption spectrum of $\left[\mathrm{Pt}_{2} \mathrm{Ag}_{23} \mathrm{Cl}_{7}\left(\mathrm{PPh}_{3}\right)_{10}\right]$ shows well-defined multiple features at 338, 364, 442, 487 and $562 \mathrm{~nm}$ (Figure 3). Its optical gap $\sim 1.5 \mathrm{eV}$ (Figure 3, inset) is close to the calculated DFT HOMO-LUMO gap $1.62 \mathrm{eV}$ for the neutral cluster. The experimental optical spectrum is in good agreement with TD-DFT results calculated for the cluster with the simplified ligands, $\left[\mathrm{Pt}_{2} \mathrm{Ag}_{23} \mathrm{Cl}_{7}\left(\mathrm{P}\left(\mathrm{CH}_{3}\right)_{3}\right)_{10}\right]$. Note that such simplification of the ligands was shown not to affect the peak positions by SOS-DFT (Figure S10). The main TD-DFT calculated excitations of $\left[\mathrm{Pt}_{2} \mathrm{Ag}_{23} \mathrm{Cl}_{7}\left(\mathrm{P}\left(\mathrm{CH}_{3}\right)_{3}\right)_{10}\right]$ are at $\sim 430$ and $571 \mathrm{~nm}$, which corresponds to the dominant experimental features at 442 and $562 \mathrm{~nm}$ (Figure 3). Much less intense calculated peaks at $482 \mathrm{~nm}$ correspond to the experimental shoulder at $487 \mathrm{~nm}$. Note that according to calculations, $\left[\mathrm{Pt}_{2} \mathrm{Ag}_{23} \mathrm{Cl}_{7}\left(\mathrm{PPh}_{3}\right)_{10}\right]$ clusters with charges +1 or +2 have HOMO-LUMO gaps $\sim 0.5 \mathrm{eV}$ and optical spectra very different from the experiment (Figure S11), confirming the zero charge-state of the cluster, consistent with SCXRD and ESI MS. 


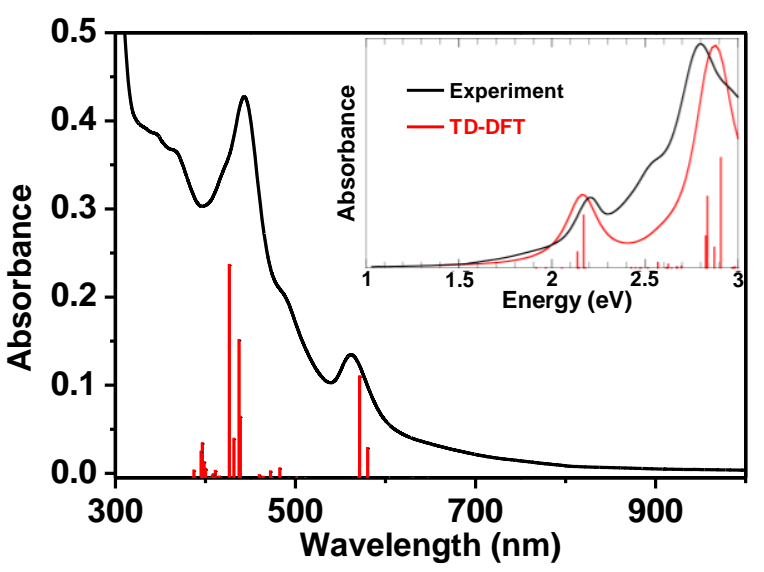

Figure 3. Experimental UV-vis spectrum of $\left[\mathrm{Pt}_{2} \mathrm{Ag}_{23} \mathrm{Cl}_{7}\left(\mathrm{PPh}_{3}\right)_{10}\right]$ (black) compared with the excitation energies and oscillator

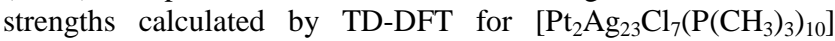
(red). Inset: corresponding UV-vis data in energy scale; the red curve was constructed via Lorentzian broadening of $0.1 \mathrm{eV}$.

TD-DFT provides further insight into the nature of the prominent excitations at $\sim 440$ and $\sim 560 \mathrm{~nm}$. The strongest contributions to these excitations come from transition from the HOMO to the LUMO+9, LUMO+10 and LUMO+2, respectively. All these orbitals are centered on the $\mathrm{Ag}$ atoms, with negligible contribution from the Pt atoms (Figure 4). Other optical transitions and the responsible molecular orbitals are given in Table S2 and Figure S12.

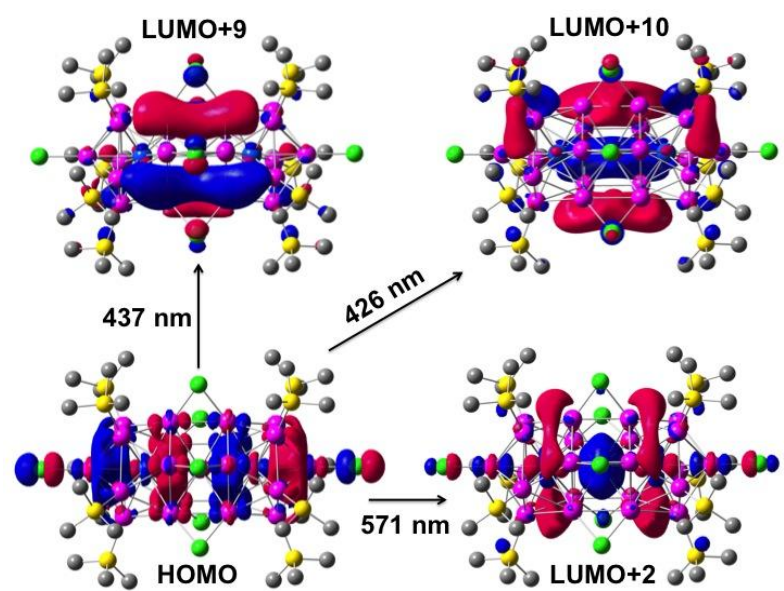

Figure 4. Orbitals with the highest contribution to the transitions at $\sim 440$ and $\sim 560 \mathrm{~nm}$. Some atoms were not displayed for clarity.

Furthermore, the cluster shows a photoluminescence peak at $678 \mathrm{~nm}$ (quantum yield: $~ 0.2$ ) upon $442 \mathrm{~nm}$ optical excitation (Figure S13). The nanosecond pump-probe analysis ${ }^{29}$ showed a good match of decay lifetime of the ground state bleach recovery at $490 \mathrm{~nm}$ with excited state absorption decay at $590 \mathrm{~nm}$ (Figure S14), suggesting the formation of a single transient species following the laser pulse excitation. The kinetic analysis of the transient decay yielded a lifetime of $393 \pm 23 \mathrm{~ns}$, providing an indication for long-lived excited state of the predominant ligand-metal charge-transfer type transitions similar to other doped $\mathrm{Ag} \mathrm{NCs} .{ }^{29}$

The Pt doping of the cluster is calculated to have a noticeable effect on its optical spectrum. Figure S15 displays the calculated optical spectrum of a hypothetical $\left[\mathrm{Ag}_{25} \mathrm{Cl}_{7}\left(\mathrm{PPh}_{3}\right)_{10}\right]^{2+}$ cluster, with 16 free valence s-electrons as in $\left[\mathrm{Pt}_{2} \mathrm{Ag}_{23} \mathrm{Cl}_{7}\left(\mathrm{PPh}_{3}\right)_{10}\right]$. Although shapes of the spectra of doped and pure $\mathrm{Ag}$ clusters are similar, the peaks in the former are blue-shifted by $0.1-0.2 \mathrm{eV}$. This is due to modulations in the electronic structure caused by heteroatom doping similar to other doped Ag NCs. ${ }^{29,30,40}$ Notably, neutral $\left[\mathrm{Ag}_{25} \mathrm{Cl}_{7}\left(\mathrm{PPh}_{3}\right)_{10}\right]$ cluster has a HOMO-LUMO gap of $<0.3 \mathrm{eV}$ and qualitatively different spectrum. The overall effect of Pt dopants on the stability of $\left[\mathrm{Pt}_{2} \mathrm{Ag}_{23} \mathrm{Cl}_{7}\left(\mathrm{PPh}_{3}\right)_{10}\right]$ is revealed by the strongly exothermic DFT mixing energy of Pt and Ag in the cluster, $-4.20 \mathrm{eV}$ per two Pt atoms (see SI for details). Such exothermicity may explain our successful synthesis of the doped clusters, but not pure Ag clusters of the same structure.

DFT calculations could attribute the absence of clusters with different degree of Pt doping to two effects. First, $\mathrm{Pt}$ atoms are highly stable in centers of two $\mathrm{Ag}$ icosahedra compared to other sites on the cluster (Figure S16), and the former sites can accommodate only two Pt atoms (Table S3). Second, $\left[\mathrm{Pt}_{2} \mathrm{Ag}_{23} \mathrm{Cl}_{7}\left(\mathrm{PPh}_{3}\right)_{10}\right]$ clusters appear to be semi-magic, i.e., they are $1.35 \mathrm{eV}$ lower in energy than the combination of hypothetical clusters with one and three Pt dopants (see SI for details). The semi-magic nature of $\left[\mathrm{Pt}_{2} \mathrm{Ag}_{23} \mathrm{Cl}_{7}\left(\mathrm{PPh}_{3}\right)_{10}\right]$ can be explained by its semi-magic number 16 valence s-electrons. ${ }^{41}$ Furthermore, anisotropic NCs such as $\left[\mathrm{Pt}_{2} \mathrm{Ag}_{23} \mathrm{Cl}_{7}\left(\mathrm{PPh}_{3}\right)_{10}\right]$ attain stability both by geometric and electronic factors, ${ }^{42}$ unlike spherical NCs, ${ }^{14,16,23}$ whose stabilities explained based on a close-shell electronic configuration.

In summary, we successfully synthesized a novel rod-shaped diplatinum-doped silver nanocluster $\left[\mathrm{Pt}_{2} \mathrm{Ag}_{23} \mathrm{Cl}_{7}\left(\mathrm{PPh}_{3}\right)_{10}\right]$ through doping strategy. Its crystal structure showed two Pt-centered $\mathrm{Ag}$ icosahedra self-assembled by vertex-sharing. The chloride ligands were found to protect the cluster through bridging and terminal binding modes. Electronic structure calculations rationalized the effect of Pt dopants on the stability of the cluster, the selective formation of clusters with two $\mathrm{Pt}$ atoms, and the origin of the transitions observed in the optical spectra. Our doping approach will motivate researchers to explore different heteroatoms-doped $\mathrm{Ag} \mathrm{NCs}$ to tailor the number of building blocks in the selfassembly, surface structure and associated properties.

\section{ASSOCIATED CONTENT}

\section{Supporting Information}

The Supporting Information is available free of charge on the ACS Publications website. Synthesis, characterization and computational details of $\left[\mathrm{Pt}_{2} \mathrm{Ag}_{23} \mathrm{Cl}_{7}\left(\mathrm{PPh}_{3}\right)_{10}\right]$ cluster (PDF).

\section{AUTHOR INFORMATION}

\section{Corresponding Authors}

*E-mail: jeanmarie.basset@kaust.edu.sa

luigi.cavallo@kaust.edu.sa

osman.bakr@kaust.edu.sa

\section{Notes}

The authors declare no competing financial interests.

\section{ACKNOWLEDGMENT}

Funding for this work was provided by KAUST.

\section{REFERENCES}

(1) Daniel, M. C.; Astruc, D. Chem. Rev. 2004, 104, 293.

(2) Jin, R.; Zeng, C.; Zhou, M.; Chen, Y. Chem. Rev. 2016, 116, 10346.

(3) Zheng, K.; Yuan, X.; Goswami, N.; Zhang, Q.; Xie, J. RSC Adv. 2014, 4, 60581

(4) Joshi, C. P.; Bootharaju, M. S.; Bakr, O. M. J. Phys. Chem. Lett. 2015, 6, 3023.

(5) Mathew, A.; Pradeep, T. Part. Part. Syst. Charact. 2014, 31, 1017.

(6) Kurashige, W.; Niihori, Y.; Sharma, S.; Negishi, Y. J. Phys. Chem. Lett. 2014, 5, 4134 .

(7) Shichibu, Y.; Negishi, Y.; Watanabe, T.; Chaki, N. K.; Kawaguchi, H.; Tsukuda, T. J. Phys. Chem. C 2007, 111, 7845. 
(8) Wickramasinghe, S.; Atnagulov, A.; Yoon, B.; Barnett, R. N.; Griffith, W. P.; Landman, U.; Bigioni, T. P. J. Am. Chem. Soc. 2015, 137, 11550.

(9) Bootharaju, M. S.; Dey, R.; Gevers, L. E.; Hedhili, M. N.; Basset, J. M.; Bakr, O. M. J. Am. Chem. Soc. 2016, 138, 13770.

(10) Salorinne, K.; Malola, S.; Wong, O. A.; Rithner, C. D.; Chen, X.; Ackerson, C. J.; Hakkinen, H. Nat. Commun. 2016, 7, 10401.

(11) Petty, J. T.; Sergev, O. O.; Ganguly, M.; Rankine, I. J.; Chevrier, D. M.; Zhang, P. J. Am. Chem. Soc. 2016, 138, 3469.

(12) Femoni, C.; Kaswalder, F.; Iapalucci, M. C.; Longoni, G.; Mehlstaubl, M.; Zacchini, S. Chem. Commun. 2005, 5769.

(13) Biltek, S. R.; Sen, A.; Pedicini, A. F.; Reber, A. C.; Khanna, S. N. J. Phys. Chem. A 2014, 118, 8314.

(14) Joshi, C. P.; Bootharaju, M. S.; Alhilaly, M. J.; Bakr, O. M. J. Am. Chem. Soc. 2015, 137, 11578.

(15) Weerawardene, K. L. D. M.; Aikens, C. M. J. Am. Chem. Soc. 2016, 138, 11202.

(16) AbdulHalim, L. G.; Bootharaju, M. S.; Tang, Q.; Del Gobbo, S.; AbdulHalim, R. G.; Eddaoudi, M.; Jiang, D.-e.; Bakr, O. M. J. Am. Chem. Soc. 2015, 137, 11970.

(17) Goswami, N.; Yao, Q.; Luo, Z.; Li, J.; Chen, T.; Xie, J. J. Phys. Chem. Lett. 2016, 7, 962

(18) Krishnadas, K. R.; Ghosh, A.; Baksi, A.; Chakraborty, I.; Natarajan, G.; Pradeep, T. J. Am. Chem. Soc. 2016, 138, 140.

(19) Wang, S.; Jin, S.; Yang, S.; Chen, S.; Song, Y.; Zhang, J.; Zhu, M. Sci. Adv. 2015, 1, e1500441.

(20) Ouyang, R.; Jiang, D.-e. ACS Catal. 2015, 5, 6624

(21) Dass, A.; Theivendran, S.; Nimmala, P. R.; Kumara, C.; Jupally, V. R.; Fortunelli, A.; Sementa, L.; Barcaro, G.; Zuo, X.; Noll, B. C. J. Am. Chem. Soc. 2015, 137, 4610.

(22) Dhayal, R. S.; Liao, J.-H.; Liu, Y.-C.; Chiang, M.-H.; Kahlal, S.; Saillard, J.-Y.; Liu, C. W. Angew. Chem. Int. Ed. 2015, 54, 3702.

(23) Desireddy, A.; Conn, B. E.; Guo, J.; Yoon, B.; Barnett, R. N.; Monahan, B. M.; Kirschbaum, K.; Griffith, W. P.; Whetten, R. L.; Landman, U.; Bigioni, T. P. Nature 2013, 501, 399.

(24) Yang, H.; Wang, Y.; Huang, H.; Gell, L.; Lehtovaara, L.; Malola, S.; Häkkinen, H.; Zheng, N. Nat. Commun. 2013, 4, 2422.

(25) Alhilaly, M. J.; Bootharaju, M. S.; Joshi, C. P.; Besong, T. M.; Emwas, A.-H.; Juarez-Mosqueda, R.; Kaappa, S.; Malola, S.; Adil,
K.; Shkurenko, A.; Häkkinen, H.; Eddaoudi, M.; Bakr, O. M. J. Am. Chem. Soc. 2016, 138, 14727.

(26) Yang, H.; Wang, Y.; Chen, X.; Zhao, X.; Gu, L.; Huang, H.; Yan, J.; Xu, C.; Li, G.; Wu, J.; Edwards, A. J.; Dittrich, B.; Tang, Z.; Wang, D.; Lehtovaara, L.; Häkkinen, H.; Zheng, N. Nat. Commun. 2016, 7, 12809 .

(27) Tofanelli, M. A.; Ni, T. W.; Phillips, B. D.; Ackerson, C. J. Inorg. Chem. 2016, 55, 999 .

(28) Yan, N.; Liao, L.; Yuan, J.; Lin, Y.-j.; Weng, L.-h.; Yang, J.; Wu, Z. Chem. Mater. 2016, 28, 8240.

(29) Bootharaju, M. S.; Joshi, C. P.; Parida, M. R.; Mohammed, O. F.; Bakr, O. M. Angew. Chem. 2016, 128, 934.

(30) Soldan, G.; Aljuhani, M. A.; Bootharaju, M. S.; AbdulHalim, L. G.; Parida, M. R.; Emwas, A.-H.; Mohammed, O. F.; Bakr, O. M. Angew. Chem. 2016, 128, 5843.

(31) Bootharaju, M. S.; Sinatra, L.; Bakr, O. M. Nanoscale 2016, 8, 17333.

(32) Jin, R.; Liu, C.; Zhao, S.; Das, A.; Xing, H.; Gayathri, C.; Xing, Y.; Rosi, N. L.; Gil, R. R.; Jin, R. ACS Nano 2015, 9, 8530.

(33) Wang, S.; Meng, X.; Das, A.; Li, T.; Song, Y.; Cao, T.; Zhu, X.; Zhu, M.; Jin, R. Angew. Chem. Int. Ed. 2014, 53, 2376.

(34) Teo, B. K.; Keating, K. J. Am. Chem. Soc. 1984, 106, 2224

(35) Teo, B. K.; Zhang, H.; Shi, X. Inorg. Chem. 1994, 33, 4086.

(36) Kappen, T. G. M. M.; Schlebos, P. P. J.; Bour, J. J.; Bosman, W. P.; Smits, J. M. M.; Beurskens, P. T.; Steggerda, J. J. Inorg. Chem. 1994, 33, 754.

(37) Teo, B. K.; Shi, X.; Zhang, H. J. Am. Chem. Soc. 1991, 113, 4329.

(38) Kang, X.; Xiong, L.; Wang, S.; Yu, H.; Jin, S.; Song, Y.; Chen, T.; Zheng, L.; Pan, C.; Pei, Y.; Zhu, M. Chem. Eur. J. 2016, 22, 17145.

(39) Teo, B. K.; Zhang, H.; Shi, X. J. Am. Chem. Soc. 1990, 112, 8552.

(40) Yan, J.; Su, H.; Yang, H.; Malola, S.; Lin, S.; Häkkinen, H.; Zheng, N. J. Am. Chem. Soc. 2015, 137, 11880.

(41) Knoppe, S.; Lehtovaara, L.; Häkkinen, H. J. Phys. Chem. A 2014 $118,4214$.

(42) Wan, X. K.; Yuan, S. F.; Lin, Z. W.; Wang, Q. M. Angew. Chem. Int. Ed. 2014, 53, 2923. 


\section{Page 5 of 5}

Journal of the American Chemical Society

1
2
3
4
5
6
7
8
9
10
11
12
13
14
15
16
17
18
19
20
21
22
23
24
25
26
27
28
29
30
31
32
33
34
35
36
37
38
39
40
41
42
43
40
45
49
50
51
52
53
55
50

Table of Contents artwork

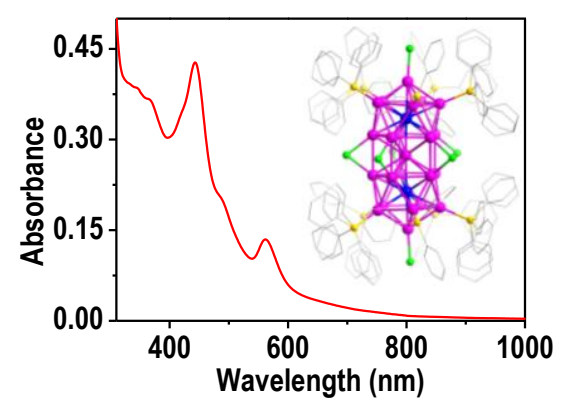

16

17

19

20

21

22

23

24

26

27

28

29

31

32

33

34

35

36

40

41

42

43

44

46

47

48

49

50

52

53

54

55

56

57

58

60 